\title{
Glucocorticoid Therapy-Induced Memory Deficits: Acute versus Chronic Effects
}

\author{
Daniel Coluccia, ${ }^{1}$ Oliver T. Wolf, ${ }^{2}$ Spyros Kollias, ${ }^{3}$ Benno Roozendaal, ${ }^{5}$ Adrian Forster, ${ }^{4,6}$ and \\ Dominique J.-F. de Quervain ${ }^{1}$ \\ ${ }^{1}$ Department of Psychiatry Research, University of Zürich, 8032 Zürich, Switzerland, ${ }^{2}$ Faculty of Psychology, Ruhr-University, 44780 Bochum, Germany, \\ ${ }^{3}$ Institute of Neuroradiology and ${ }^{4}$ Department of Rheumatology and Institute for Physical Medicine, University Hospital of Zürich, 8091 Zürich, \\ Switzerland, ${ }^{5}$ Center for the Neurobiology of Learning and Memory and Department of Neurobiology and Behavior, University of California, Irvine, \\ California 92697-3800, and ${ }^{6}$ Rehabilitation Clinic St. Katharinental, 8253 Diessenhofen, Switzerland
}

Conditions with chronically elevated glucocorticoid levels are usually associated with declarative memory deficits. Considerable evidence suggests that long-term glucocorticoid exposure may cause cognitive impairment via cumulative and long-lasting influences on hippocampal function and morphology. However, because elevated glucocorticoid levels at the time of retention testing are also known to have direct impairing effects on memory retrieval, it is possible that such acute hormonal influences on retrieval processes contribute to the memory deficits found with chronic glucocorticoid exposure. To investigate this issue, we examined memory functions and hippocampal volume in 24 patients with rheumatoid arthritis who were treated either chronically (5.3 \pm 1.0 years, mean $\pm \mathrm{SE})$ with low to moderate doses of prednisone $(7.5 \pm 0.8 \mathrm{mg}$, mean $\pm \mathrm{SE})$ or without glucocorticoids. In both groups, delayed recall of words learned $24 \mathrm{~h}$ earlier was assessed under conditions of either elevated or basal glucocorticoid levels in a double-blind, placebo-controlled crossover design. Although the findings in this patient population did not provide evidence for harmful effects of a history of chronic prednisone treatment on memory performance or hippocampal volume per se, acute prednisone administration $1 \mathrm{~h}$ before retention testing to either the steroid or nonsteroid group impaired word recall. Thus, these findings indicate that memory deficits observed under chronically elevated glucocorticoid levels result, at least in part, from acute and reversible glucocorticoid effects on memory retrieval.

Key words: glucocorticoids; prednisone; memory; retrieval; hippocampus; MRI

\section{Introduction}

Sustained endogenous hypercortisolemia, such as found in depression, Cushing's disease or human aging, is often associated with declarative memory impairment (Rubinow et al., 1984; Starkman et al., 1992; Seeman et al., 1997; Lupien et al., 1998). Moreover, prolonged glucocorticoid therapy, which is widely used in clinical practice, is known to induce cognitive deficits (Keenan et al., 1996; Wolkowitz et al., 1997; Brown et al., 2004; Bermond et al., 2005; Brunner et al., 2005). Animal and human studies investigating the neurobiological basis of such memory deficits suggested that chronic exposure to glucocorticoids can cause declarative memory impairment via cumulative and longlasting detrimental influences on hippocampal function, including altered adrenal steroid receptor density, neurotransmitter content and dendritic atrophy (Starkman et al., 1992; Sapolsky, 2000; Joëls, 2001; McEwen, 2001; Brown et al., 2004). However, because in studies investigating the effects of chronic glucocorticoid exposure memory testing also takes place under conditions

Received 0ct. 30, 2007; revised Jan. 24, 2008; accepted Feb. 4, 2008

This work was supported by Swiss National Science Foundation Grant PP00B-106708 to D.J.-F.d.Q. and German Research Foundation Grant DFG W0 733/7-1 to 0.T.W.

Correspondence should be addressed to Dominique J.-F. de Quervain, Division of Psychiatry Research, University of Zürich, Lenggstrasse 31,8032 Zürich, Switzerland. E-mail: quervain@bli.unizh.ch.

DOI:10.1523/JNEUROSCI.4893-07.2008

Copyright $\odot 2008$ Society for Neuroscience $\quad$ 0270-6474/08/283474-05\$15.00/0 of elevated glucocorticoid levels, it is possible that direct influences of glucocorticoids on cognitive performance contribute to these memory deficits. Whereas acutely administered glucocorticoids are known to dose-dependently enhance memory consolidation (Roozendaal, 2000; Buchanan and Lovallo, 2001), it is well established that acutely elevated glucocorticoid levels at the time of retention testing impair the retrieval of previously acquired information (De Quervain et al., 1998, 2000, 2003; Wolf et al., 2001; Het et al., 2005; Buchanan et al., 2006). For example, we have shown previously that a single administration of cortisone (25 mg) $1 \mathrm{~h}$ before retention testing impairs free recall of words that have been learned $24 \mathrm{~h}$ earlier (De Quervain et al., 2000). Such acute effects of glucocorticoids on memory retrieval are limited to the time that circulating hormone levels are elevated (De Quervain et al., 1998) and known to involve the hippocampus (De Quervain et al., 2003; Roozendaal et al., 2003; Oei et al., 2007). To investigate whether such acute glucocorticoid effects on memory retrieval processes are involved in mediating the memory deficits observed in conditions of chronic glucocorticoid excess, we assessed memory functions and hippocampal volume in patients with rheumatoid arthritis who were treated either chronically with prednisone at low to moderate and widely used doses (Bijlsma et al., 2005) or without glucocorticoids and then manipulated glucocorticoid levels shortly before retention testing. 


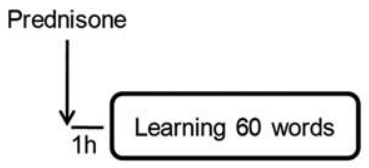

Prednisone / Placebo

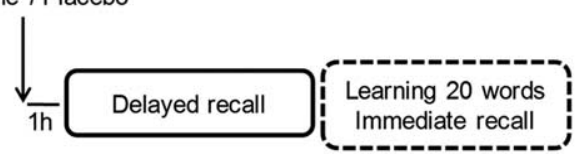

Day 1

Day 2

Figure 1. Study design. Glucocorticoid levels were manipulated at the time of retention testing (for details, see Materials and Methods).

\section{Materials and Methods \\ Subjects}

Twenty-four male $(n=8)$ and female $(n=16)$ patients with rheumatoid arthritis according to the diagnostic criteria of the American College of Rheumatology (mean disease duration in months \pm SE, $160.3 \pm 26.4$, range $24-516$ ), aged $41-65$ years (mean \pm SE, $55.2 \pm 1.6$ ) participated in this study. The inclusion criterion for the group treated chronically with prednisone (steroid group; $n=13$ ) was a continuous und current daily prednisone medication (between 5 and $15 \mathrm{mg}$ ) for at least 1 year. The nonsteroid group $(n=11)$ consisted of patients without or only sporadic lifetime glucocorticoid use (i.e., not within the last 6 months) and was matched to the steroid group on disease activity as measured with the Disease Activity Score (Prevoo et al., 1995) and the Rheumatoid Arthritis Disease Activity Index (Stucki et al., 1995) and duration. The therapy of these patients was based on disease modifying anti-rheumatic drugs, including tumor necrosis factor- $\alpha$ blockers, and nonsteroidal antiinflammatory drugs. The decision to use steroid medication or disease modifying anti-rheumatic drugs was based on doctor's and/or patient's preference (personal risk-benefit analysis). Exclusion criteria for both groups were psychiatric or neurological disease according to the International Statistical Classification of Diseases, 10th revision, severe somatic disease other than rheumatoid arthritis, psychotropic medication, or contraindication for magnetic resonance imaging (MRI). Subjects gave written informed consent to participate in the study, and all methods and experimental procedures were approved by the ethical committee of the University of Zürich, Switzerland.

\section{Procedure and measurements}

We used a placebo-controlled, double-blind, crossover design. Immediately after arrival to the laboratory on day 1 , the steroid group took the daily prednisone dose and the nonsteroid group received $5 \mathrm{mg}$ of prednisone (Prednison Streuli Pharma, Uznach, Switzerland) to produce similar circulating glucocorticoid levels at learning and during memory consolidation (Fig. 1). One hour later, subjects were presented a list of 60 unrelated German nouns (De Quervain et al., 2000). The words were presented (each word for $4 \mathrm{~s}$ ) twice in a different order on a computer screen with the instruction to learn them for delayed recall testing. There was no further prednisone medication in either group until retention testing $24 \mathrm{~h}$ after learning. At that time, the steroid group received either prednisone at the usual daily dose or a similar looking placebo, and the nonsteroid group received either $5 \mathrm{mg}$ of prednisone or placebo. One hour later, free recall was tested for which subjects were asked to write down all the words they could remember (see Fig. 1). After this delayed free-recall test, an immediate recall test was performed with another set of 20 words, which was only presented once. After a 2 week wash-out period, during which patients continued with their usual treatment regimen, the procedure was repeated in the same individuals with other sets of words and with the study medication they had not received the first time (in a double-blind manner). The order of the study medication was balanced across subjects. All learning and testing procedures were performed between 1:00 P.M. and 4:00 P.M.

\section{Salivary cortisol}

Saliva for hormone measurement was sampled on day 2 before the acute administration of the study medication (prednisone or placebo) and $1 \mathrm{~h}$ later immediately before retention testing with the Salivette sampling device (Sarstedt, Nuembrecht, Germany). Cortisol was analyzed using a commercially available immunoassay (CLIA; IBL, Hamburg, Germany).
MRI hippocampus volumetry

MRI Acquisition. Subjects were examined on a 1.5 T MRI system (General Electric, Fairfield, CT) within 4 weeks after memory testing. T1weighted [three-dimensional spoiled gradient echo; repetition time (TR), $35 \mathrm{~ms}$; echo time (TE), 9 ms; flip angle, $30^{\circ}$; matrix, $256 \times 256$ $\mathrm{mm}$; field of view, $240 \mathrm{~mm}$; slice thickness, 0.8 $\mathrm{mm}$ ] images (124 slices obtained in sagittal plane) were used for volumetry. Additional structural imaging included axial proton density- and T2-weighted double-echo fast spin-echo sequences (TR, $3500 \mathrm{~ms}$; TE, 12/102 ms; 2 numbers of excitations; slice thickness/gap, 4/1 mm).

Volumetric analysis. Manual volumetric measurements were performed by one of the authors (O.T.W.), who was blind with respect to the treatment of the patients (i.e., steroid or nonsteroid group), using methods with previously published high reliability and validity (Convit et al., 1999; Bobinski et al., 2000; Lobnig et al., 2006). In brief, reformatted coronal images (1.5 mm slice thickness) were used. The hippocampus (cornu ammonis, dentate gyrus, and subiculum) was measured in its entire extension using multiple image orientations (Lobnig et al., 2006). A cerebral vault volume was obtained by measuring the compartment bounded by the dura and the tentorium cerebri on every tenth slice (Lobnig et al., 2006). A measure of global CSF, and thus of global cerebral atrophy, was determined using a threshold procedure (Lobnig et al., 2006).

\section{Statistics}

Group differences in demographic and clinical characteristics were analyzed with unpaired $t$ tests. Chronic and acute treatment effects on immediate and delayed recall were analyzed with repeated-measures ANOVAs with chronic treatment (prednisone vs steroid-free medication) as a between-subject factor and acute administration of study medication at the time of retention testing (prednisone vs placebo) as a within-subject factor. As the two treatment groups significantly differed in age, we included age as covariate. Group differences in brain volumes and salivary cortisol concentrations were analyzed with ANCOVAs with age as covariate.

\section{Results}

The steroid and nonsteroid groups differed significantly in age, with patients treated without prednisone being younger (Table 1). This difference may reflect the trend toward less steroidal therapy over the last decade. Otherwise, there were no significant differences in demographic or clinical data between the two groups (Table 1).

The ANOVA for delayed recall with chronic treatment (prednisone vs steroid-free medication) as a between-subject factor and acute administration of study medication at testing (prednisone vs placebo) as a within-subject factor revealed a significant effect of acute prednisone administration $(F=6.0 ; \mathrm{df}=1,21 ; p=$ $0.02)$, but not of chronic treatment $(F=0.2 ; \mathrm{df}=1,21 ; p=0.7)$ (Table 2). There was no significant interaction between acute and chronic treatment effects $(F=0.2$; df $=1,21 ; p=0.7)$. Furthermore, in the steroid group there were no significant correlations of dose or duration of chronic prednisone treatment with memory performance under acute prednisone or placebo medication (all $p$ values $>0.3$, Pearson's correlation).

For immediate recall, there was no significant effect of either acute $(F=0.2 ; \mathrm{df}=1,21 ; p=0.7)$ or chronic prednisone treatment $(F=0.3 ; \mathrm{df}=1,21 ; p=0.6)$, or their interaction $(F=0.1$; $\mathrm{df}=1,21 ; p=0.3)$ (Table 2).

MRI volumetry revealed no significant differences between the steroid and nonsteroid groups for left or right hippocampal volume, cerebral vault volume or global CSF volume (all $p$ val- 
ues $>0.7)$ (Table 3). Furthermore, in the steroid group there were no significant correlations of dose or duration of chronic prednisone treatment with left or right hippocampal volume, cerebral vault volume or global CSF volume (all $p$ values $>$ 0.1 , Pearson's correlation).

Salivary cortisol concentrations assessed immediately before or $1 \mathrm{~h}$ after acute prednisone or placebo administration on day 2 did not differ between the two treatment groups (all $p$ values $>0.4$ ) (Table 3). Because of cross-reactivity of the cortisol immunoassay with prednisone and its active metabolite prednisolone, the assay showed elevated levels $1 \mathrm{~h}$ after acute prednisone medication compared with cortisol levels before medication $(p<$ 0.01 , for both treatment groups, paired $t$ tests). As the elimination half-life of prednisolone is 2-4 h (Czock et al., 2005), cross-reactivity with prednisolone $24 \mathrm{~h}$ after the last intake of prednisone is negligible. Therefore, the finding of similar cortisol levels between the treatment groups immediately before the acute prednisone administration, i.e., $24 \mathrm{~h}$ after the last steroid application, indicates that the chronic prednisone treatment did not result in a lasting suppression of the hypothalamuspituitary-adrenal axis.

\section{Discussion}

The present study investigated whether acute and reversible glucocorticoid effects on memory retrieval contribute to the memory deficits observed under chronic glucocorticoid treatment. We therefore manipulated glucocorticoid levels at the time of memory retention testing in patients with rheumatoid arthritis who were treated either chronically with prednisone or without glucocorticoids. Whereas we did not find evidence for harmful effects of the chronic prednisone treatment on memory performance or hippocampal volume, acute administration of prednisone before retention testing impaired delayed recall of verbal memory. These findings are in line with the results of our previous studies indicating that an acute elevation of glucocorticoid levels at the time of retention testing impairs the retrieval of long-term spatial and contextual memory in rats and declarative memory in healthy humans (De Quervain et al., 1998, 2000; Roozendaal et al., 2003, 2004; Het et al., 2005; Kuhlmann et al., 2005a,b). Also consistent with our previous reports, we found a selective interference of acutely elevated glucocorticoid levels with delayed, but not immediate recall (De Quervain et al., 2000; Kuhlmann and Wolf, 2006). From other studies, however, there is also evidence that glucocorticoids can affect working memory (Wolf et al., 2001) and immediate recall (Brunner et al., 2005), indicating that glucocorticoid effects on short-term memory processes depend on the experimental design (e.g., task or dose used). In addition to previous findings, the present study shows that the acute glucocorticoid effect on memory retrieval is also observed with the glucocorticoid prednisone. Furthermore, and also extending previous evi-

$\begin{array}{ccl}\text { Steroid group } & \text { Nonsteroid group } & p \\ 8 / 5 & 8 / 3 & 0.68 \\ 59.4 \pm 1.5 & 50.3 \pm 2.2 & 0.002 \\ 9.0 \pm 0.4 & 10.4 \pm 0.8 & 0.13 \\ 10.4 \pm 2.4 & 13.6 \pm 1.9 & 0.33 \\ 3.1 \pm 0.5 & 3.4 \pm 0.3 & 0.56 \\ 3.1 \pm 0.4 & 3.1 \pm 0.5 & 0.98 \\ 5.7 \pm 2.0 & 5.2 \pm 1.3 & 0.84 \\ 147.2 \pm 43.6 & 175.8 \pm 27.6 & 0.60 \\ 7.5 \pm 0.8 & & \\ 63.7 \pm 11.8 & & \end{array}$

$63.7 \pm 11.8$

Table 1. Demographic and clinical data

Table 2. Effects of acute and chronic glucocorticoid treatment on memory

Table 3. Brain volumes and salivary cortisol concentrations

\begin{tabular}{|c|c|c|c|}
\hline \multicolumn{2}{|c|}{ Steroid group } & \multicolumn{2}{|c|}{ Nonsteroid group } \\
\hline $\begin{array}{l}\text { Acute } \\
\text { placebo }\end{array}$ & $\begin{array}{l}\text { Acute } \\
\text { prednisone }\end{array}$ & $\begin{array}{l}\text { Acute } \\
\text { placebo }\end{array}$ & $\begin{array}{l}\text { Acute } \\
\text { prednisone }\end{array}$ \\
\hline $13.9 \pm 2.8$ & $10.9 \pm 1.9$ & $14.8 \pm 3.1$ & $12.9 \pm 2.2$ \\
\hline $9.1 \pm 0.8$ & $8.8 \pm 0.9$ & $7.9 \pm 0.9$ & $8.6 \pm 1.0$ \\
\hline
\end{tabular}

ednisone medication; nonsteroid group, group without chronic glucocorticoid medication.

\begin{tabular}{lccc}
\hline & Steroid group & Nonsteroid group & $p$ \\
\hline Hippocampus right $\left(\mathrm{cm}^{3}\right)$ & $2.58 \pm 0.088$ & $2.60 \pm 0.093$ & 0.87 \\
Hippocampus left $\left(\mathrm{cm}^{3}\right)$ & $2.49 \pm 0.079$ & $2.47 \pm 0.084$ & 0.89 \\
Cerebral vault volume $\left(\mathrm{cm}^{3}\right)$ & $1171.7 \pm 37.4$ & $1188.7 \pm 39.6$ & 0.78 \\
Global CSF volume $\left(\mathrm{cm}^{3}\right)$ & $163.3 \pm 11.5$ & $158.0 \pm 12.2$ & 0.78 \\
Cort before placebo $(\mathrm{nmol} / \mathrm{L})$ & $5.0 \pm 0.9$ & $4.3 \pm 0.9$ & 0.66 \\
Cort before prednisone $(\mathrm{nmol} / \mathrm{L})$ & $5.4 \pm 1.1$ & $4.2 \pm 1.2$ & 0.53 \\
Cort 1 $\mathrm{h}$ after placebo $(\mathrm{nmol} / \mathrm{L})$ & $4.2 \pm 1.1$ & $5.7 \pm 1.2$ & 0.42 \\
Cort $1 \mathrm{~h}$ after prednisone $(\mathrm{nmol} / \mathrm{L})$ & $20.6 \pm 3.5^{a}$ & $17.5 \pm 3.8^{a}$ & 0.60
\end{tabular}

Data are presented as mean \pm SE. Steroid group, Group with chronic prednisone medication; nonsteroid group, group without chronic glucocorticoid medication; Cort, cortisol concentration.

-reactivity with prednisone and its active metabolite prednisolone.

dence, the present findings indicate that the impairing effect of pretesting administration of prednisone was not attributable to state dependency (different glucocorticoid levels at learning and retrieval) because glucocorticoid levels in both treatment groups were also elevated during learning.

The findings of the present study are remarkable as they indicate that declarative memory was not impaired $24 \mathrm{~h}$ after discontinuation of the chronic glucocorticoid treatment, i.e., when memory recall was tested under normalized glucocorticoid levels after placebo administration. Previous studies have tested recovery of memory function only after a substantial longer recovery time (Brunner et al., 2005). The present findings indicate that acute and direct glucocorticoid effects but not the history of chronic glucocorticoid treatment played a role in inducing memory deficits. In the present study, we investigated patients treated with low to moderate doses of prednisone (between 5 and $15 \mathrm{mg}$ ), which are widely used in clinical practice (Lim and Conn, 2001; Bijlsma et al., 2005). These doses, at the treatment durations investigated, did not induce any changes in hippocampal volume. It is possible that memory deficits related to a history of chronic treatment only appear at higher doses, or when associated with clear effects on hippocampal morphology or volume. For example, a previous study reported smaller hippocampal volumes and 
memory deficits in patients treated chronically with a mean dose of $15.6 \mathrm{mg}$ of prednisone for a mean duration of 92 months compared with control patients not treated with corticosteroids (Brown et al., 2004). However, in that study, no significant correlation was found between hippocampal volume and memory performance, suggesting that direct glucocorticoid effects on memory performance also played an important role. Moreover, another study investigating the effects of chronic prednisone treatment (doses between 5 and $40 \mathrm{mg} / \mathrm{d}$, durations between 1 and 15 years) found that the memory-impairing effect of prednisone did not depend on dose or duration of the treatment, further suggesting that direct glucocorticoid effects on memory performance are important (Keenan et al., 1996). However, evidence from Cushing's disease patients indicated slow recovery of both hippocampal volumes and memory functions after treatment-induced lowering of cortisol levels (Starkman et al., 1999, 2003), suggesting that, in this condition, the memory impairment may be related to the smaller hippocampi. However, alternative explanations are possible, as previous evidence indicates that memory deficits that occur after lesioning the CA3 region of the hippocampus in rats are not caused by the structural loss, but rather related to elevated glucocorticoid levels because of a lesion-induced disinhibition of hypothalamus-pituitary-adrenal axis activity (Roozendaal et al., 2001). These deficits could be blocked by a pharmacological inhibition of glucocorticoid synthesis before memory retrieval testing. Other findings in rats indicated that an attenuation of glucocorticoid levels at the time of memory assessment prevented chronic stress-induced impairments in spatial memory (Wright et al., 2006), under conditions known to induce atrophy of hippocampal neurons (Conrad et al., 1999). Altogether, it is likely that acute glucocorticoid effects on memory retrieval, even in the presence of hippocampal atrophy, participate in inducing memory deficits associated with chronically elevated glucocorticoid levels.

In summary, although the present study investigating rheumatoid arthritis patients treated chronically with low to moderate doses of prednisone did not provide evidence for harmful effects on memory performance related to the chronic treatment, elevated glucocorticoid levels at the time of retention testing induced memory retrieval impairment. These findings suggest that memory deficits observed in conditions with chronically elevated glucocorticoid levels may result, at least in part, from acute and reversible glucocorticoid effects on memory retrieval.

\section{References}

Bermond B, Surachno S, Lok A, ten Berge IJ, Plasmans B, Kox C, Schuller E, Schellekens PT, Hamel R (2005) Memory functions in prednisonetreated kidney transplant patients. Clin Transplant 19:512-517.

Bijlsma JW, Saag KG, Buttgereit F, Da Silva JA (2005) Developments in glucocorticoid therapy. Rheum Dis Clin North Am 31:1-17.

Bobinski M, de Leon MJ, Wegiel J, Desanti S, Convit A, Saint Louis LA, Rusinek H, Wisniewski HM (2000) The histological validation of post mortem magnetic resonance imaging-determined hippocampal volume in Alzheimer's disease. Neuroscience 95:721-725.

Brown ES, Woolston J, Frol A, Bobadilla L, Khan DA, Hanczyc M, Rush AJ, Fleckenstein J, Babcock E, Cullum CM (2004) Hippocampal volume, spectroscopy, cognition, and mood in patients receiving corticosteroid therapy. Biol Psychiatry 55:538-545.

Brunner R, Schaefer D, Hess K, Parzer P, Resch F, Schwab S (2005) Effect of corticosteroids on short-term and long-term memory. Neurology 64:335-337.

Buchanan TW, Lovallo WR (2001) Enhanced memory for emotional material following stress-level cortisol treatment in humans. Psychoneuroendocrinology 26:307-317.

Buchanan TW, Tranel D, Adolphs R (2006) Impaired memory retrieval cor- relates with individual differences in cortisol response but not autonomic response. Learn Mem 13:382-387.

Conrad CD, LeDoux JE, Magarinos AM, McEwen BS (1999) Repeated restraint stress facilitates fear conditioning independently of causing hippocampal CA3 dendritic atrophy. Behav Neurosci 113:902-913.

Convit A, McHugh P, Wolf OT, de Leon MJ, Bobinski M, De SS, Roche A, Tsui W (1999) MRI volume of the amygdala: a reliable method allowing separation from the hippocampal formation. Psychiatry Res 90:113-123.

Czock D, Keller F, Rasche FM, Haussler U (2005) Pharmacokinetics and pharmacodynamics of systemically administered glucocorticoids. Clin Pharmacokinet 44:61-98.

De Quervain DJ, Roozendaal B, McGaugh JL (1998) Stress and glucocorticoids impair retrieval of long-term spatial memory. Nature 394:787-790.

De Quervain DJ, Roozendaal B, Nitsch RM, McGaugh JL, Hock C (2000) Acute cortisone administration impairs retrieval of long-term declarative memory in humans. Nat Neurosci 3:313-314.

De Quervain DJ, Henke K, Aerni A, Treyer V, McGaugh JL, Berthold T, Nitsch RM, Buck A, Roozendaal B, Hock C (2003) Glucocorticoidinduced impairment of declarative memory retrieval is associated with reduced blood flow in the medial temporal lobe. Eur J Neurosci 17:1296-1302.

Het S, Ramlow G, Wolf OT (2005) A meta-analytic review of the effects of acute cortisol administration on human memory. Psychoneuroendocrinology 30:771-784.

Joëls M (2001) Corticosteroid actions in the hippocampus. J Neuroendocrinol 13:657-669.

Keenan PA, Jacobson MW, Soleymani RM, Mayes MD, Stress ME, Yaldoo DT (1996) The effect on memory of chronic prednisone treatment in patients with systemic disease. Neurology 47:1396-1402.

Kuhlmann S, Wolf OT (2006) Arousal and cortisol interact in modulating memory consolidation in healthy young men. Behav Neurosci 120:217-223.

Kuhlmann S, Kirschbaum C, Wolf OT (2005a) Effects of oral cortisol treatment in healthy young women on memory retrieval of negative and neutral words. Neurobiol Learn Mem 83:158-162.

Kuhlmann S, Piel M, Wolf OT (2005b) Impaired memory retrieval after psychosocial stress in healthy young men. J Neurosci 25:2977-2982.

Lim SS, Conn DL (2001) The use of low-dose prednisone in the management of rheumatoid arthritis. Bull Rheum Dis 50:1-4.

Lobnig BM, Kromeke O, Optenhostert-Porst C, Wolf OT (2006) Hippocampal volume and cognitive performance in long-standing type 1 diabetic patients without macrovascular complications. Diabet Med 23:32-39.

Lupien SJ, de Leon M, De Santi S, Convit A, Tarshish C, Nair NP, Thakur M, McEwen BS, Hauger RL, Meaney MJ (1998) Cortisol levels during human aging predict hippocampal atrophy and memory deficits. Nat Neurosci 1:69-73.

McEwen BS (2001) Plasticity of the hippocampus: adaptation to chronic stress and allostatic load. Ann NY Acad Sci 933:265-277.

Oei NY, Elzinga BM, Wolf OT, Ruiter MB, Damoiseaux JS, Kuijer JP, Veltman DJ, Scheltens P, Rombouts SA (2007) Glucocorticoids decrease hippocampal and prefrontal activation during declarative memory retrieval in young men. Brain Imaging Behav 1:31-41.

Prevoo ML, van 't Hof MA, Kuper HH, van Leeuwen MA, van de Putte LB, van Riel PL (1995) Modified disease activity scores that include twentyeight-joint counts. Development and validation in a prospective longitudinal study of patients with rheumatoid arthritis. Arthritis Rheum 38:44-48.

Roozendaal B (2000) 1999 Curt P. Richter award. Glucocorticoids and the regulation of memory consolidation. Psychoneuroendocrinology 25:213-238.

Roozendaal B, Phillips RG, Power AE, Brooke SM, Sapolsky RM, McGaugh JL (2001) Memory retrieval impairment induced by hippocampal CA3 lesions is blocked by adrenocortical suppression. Nat Neurosci 4:1169-1171.

Roozendaal B, Griffith QK, Buranday J, De Quervain DJ, McGaugh JL (2003) The hippocampus mediates glucocorticoid-induced impairment of spatial memory retrieval: dependence on the basolateral amygdala. Proc Natl Acad Sci USA 100:1328-1333.

Roozendaal B, De Quervain DJ, Schelling G, McGaugh JL (2004) A systemically administered beta-adrenoceptor antagonist blocks corticosterone- 
induced impairment of contextual memory retrieval in rats. Neurobiol Learn Mem 81:150-154.

Rubinow DR, Post RM, Savard R, Gold PW (1984) Cortisol hypersecretion and cognitive impairment in depression. Arch Gen Psychiatry 41:279-283.

Sapolsky RM (2000) Glucocorticoids and hippocampal atrophy in neuropsychiatric disorders. Arch Gen Psychiatry 57:925-935.

Seeman TE, McEwen BS, Singer BH, Albert MS, Rowe JW (1997) Increase in urinary cortisol excretion and memory declines: MacArthur studies of successful aging. J Clin Endocrinol Metab 82:2458 -2465.

Starkman MN, Gebarski SS, Berent S, Schteingart DE (1992) Hippocampal formation volume, memory dysfunction, and cortisol levels in patients with Cushing's syndrome. Biol Psychiatry 32:756-765.

Starkman MN, Giordani B, Gebarski SS, Berent S, Schork MA, Schteingart DE (1999) Decrease in cortisol reverses human hippocampal atrophy following treatment of Cushing's disease. Biol Psychiatry 46:1595-1602.
Starkman MN, Giordani B, Gebarski SS, Schteingart DE (2003) Improvement in learning associated with increase in hippocampal formation volume. Biol Psychiatry 53:233-238.

Stucki G, Liang MH, Stucki S, Bruhlmann P, Michel BA (1995) A selfadministered rheumatoid arthritis disease activity index (RADAI) for epidemiologic research. Psychometric properties and correlation with parameters of disease activity. Arthritis Rheum 38:795-798.

WolfOT, Convit A, McHugh PF, Kandil E, Thorn EL, De Santi S, McEwen BS, de Leon MJ (2001) Cortisol differentially affects memory in young and elderly men. Behav Neurosci 115:1002-1011.

Wolkowitz OM, Reus VI, Canick J, Levin B, Lupien S (1997) Glucocorticoid medication, memory and steroid psychosis in medical illness. Ann NY Acad Sci 823:81-96.

Wright RL, Lightner EN, Harman JS, Meijer OC, Conrad CD (2006) Attenuating corticosterone levels on the day of memory assessment prevents chronic stress-induced impairments in spatial memory. Eur J Neurosci 24:595-605. 